\title{
KOMPARASI PENGELOLAAN TANAMAN JAGUNG SISTEM OLAH TANAH SEMPURNA DENGAN SISTEM TANPA OLAH TANAH (TOT) DI KABUPATEN OKU TIMUR
}

\author{
(Sugeng Supriyanto)
}

\begin{abstract}
The objectives of this research are: (1) To know the income of corn farmer farmers between the perfect soil system with TOT system in OKU Timur Regency, (2) To know the comparison of management of maize plant between the perfect soil system and the system (TOT) in Kabupaten OKU Timur, (3) To determine the feasibility level of corn cultivation business between a perfect soil system and TOT system in East OKU Regency. This research was conducted in OKU Timur Regency. This research was conducted in April 2015 until June 2015 with a survey method focused on corn farming practices with either a groundless (TOT) system or a perfect soil system in East OKU district. This study found that the average cost of production for the management of corn business activities with the system Without Sports Land (TOT) of Rp. 11.296.925, - / yr, with a flat fee of Rp. 1.088.896, - / Thn, and variable cost of Rp. 10.208.029, - / yr. Receipt is $R p$. 29.139.583, - / Thn then the revenue is $R p .17,842,658$, - / yr (Rp 5,947,553, - / MT or Rp 1,486,888, / bln). While the average cost of production on corn management business activities with a perfect tillage system of Rp. 12.998.688, - / yr, with a fixed fee of Rp. 1.086.254, - / yr, and variable cost of Rp. 11.912.434, - / yr. While the revenue is Rp. 31.819.792, - / Thn then the income is obtained by Rp. 18.821.104, - / yr (Rp 6.273.701, - / MT or Rp 1,568,425, - / month). The comparative value of corn management business with the landless (TOT) system is Rp. 17.842.658, - / MT. While on the management of corn with a perfect soil system is Rp. 18.821.104, - / MT obtained from the final difference with the cost of production. Thus, there is a difference in income of Rp. 978.446, - / MT (Rp 244,611, - / Month). The management of maize with Soil Extract (TOT) and perfect soil system in East OKU Regency can be said to be profitable and feasible, because the average value is obtained $R / C$ Ratio 2.58 which means $>1$ then the business is considered profitable, and Also obtained the value of B / C Ratio 1.58 which means $>0$, then the business declared feasible
\end{abstract}

Key Words : Business Feasibility Study, Transfer of Land Function, Corn Plant, and Income.

\section{PENDAHULUAN}

\section{A. Latar Belakang}

Pembangunan pertanian dilakukan dibeberapa sektor antara lain subsektor pertanian tanaman pangan, subsektor perkebunan, subsektor peternakan dan subsektor perikanan. Peningkatan produksi sektor pertanian dapat dilakukan melalui beberapa program pemerintah yaitu intensifikasi, ekstensifikasi, diversifikasi dan rehabilitasi. Tujuan dari kegiatan tersebut adalah untuk meningkatkan pendapatan dan taraf hidup petani. Jadi salah satu sasaran pembangunan pertanian adalah untuk kesejahteraan keluarga petani, karena untuk mencapai keluarga sejahtera perlu adanya peningkatan pendapatan dan pengaturan penggunaan pendapatan (Departemen Pertanian dan Ketahanan Pangan, 2001).

Salah satu subsektor tanaman pangan selain beras yang perlu diperhatikan adalah jagung. Hal tersebut dikarenakan jagung merupakan salah satu bahan makanan pokok setelah beras, selain itu jagung juga merupakan bahan baku makanan ternak. Oleh sebab itu, jagung menjadi kebutuhan yang cukup penting bagi kehidupan manusia dan hewan. Jagung mempunyai kandungan gizi dan serat kasar yang cukup memadai sebagai bahan makanan pokok pengganti beras. Kebutuhan akan konsumsi jagung di Indonesia terus meningkat. Hal tersebut didasarkan pada semakin meningkatnya tingkat konsumsi perkapita per tahun dan semakin meningkatnya jumlah penduduk Indonesia. Jagung di Indonesia merupakan komoditi tanaman pangan penting selain beras, akan tetapi tingkat produksinya saat ini belum optimal. Walaupun sebenarnya produksi jagung di Indonesia dari tahun ke tahun terus meningkat, akan tetapi tetap saja belum dapat memenuhi kebutuhan jagung di Indonesia (Prabowo, 2010).

Produksi tanaman pangan di Indonesia ke depan diharapkan dapat optimal, karena Indonesia merupakan salah satu negara yang mempunyai jumlah penduduk terbanyak di dunia, jumlah tersebut terus meningkat seiring dengan bertambahnya waktu. Peningkatan jumlah penduduk tersebut mengakibatkan kebutuhan bahan pangan dan kebutuhan akan papan juga semakin meningkat. Peningkatan jumlah penduduk tersebut otomatis harus diimbangi 
dengan peningkatan bahan pangan yang sangat dibutuhkan oleh manusia. Akan tetapi kenyataannya, pada saat ini produksi bahan makanan pokok penduduk Indonesia semakin berkurang, hal tersebut semakin diperparah dengan semakin menyempitnya lahan pertanian karena penggunaan lahan pertanian untuk pemukiman (Hadiyanto, 2003).

Salah satu faktor yang mempengaruhi produksi jagung di Indonesia adalah sistem pengolahan tanah, karena dapat mempengaruhi besarnya biaya yang dikeluarkan oleh petani. Selain itu, sistem pengolahan tanah akan mempengaruhi jagung yag dihasilkan, jika pengolahan tanahnya tepat maka jagung yang dihasilkan dapat maksimal. Petani jagung di Indonesia mengenal dua sistem pengolahan tanah yaitu pengolahan tanah secara sempurna dan sistem tanpa olah tanah (TOT). Sistem pengolahan tanah sempurna biasanya dilakukan pada lahan yang belum pernah digunakan, sehingga perlu dilakukan pengolahan tanah \pm 3 kali agar tanah menjadi subur. Sedangkan, sistem tanpa olah tanah lebih cocok dilakukan pada lahan yang sudah pernah digarap, sehingga cukup dilakukan pembersihan gulma dengan melakukan penyemprotan menggunakan herbisida karena dengan demikian dapat sangat menghemat biaya (Pardede, 2009).

Seorang petani saat akan melakukan budidaya jagung sangat perlu memperhatikan sistem pengolahan tanah yang akan diterapkan, karena sangat berpengaruh terhadap pendapatan yang akan diperoleh petani. Petani harus menyesuaikan kondisi lahan garapan agar sistem pengolahan tanah yang diterapkan dapat tepat guna. Salah satu contohnya di Kabupaten OKU Timur banyak petani jagung yang menggunakan sistem tanpa olah tanah (TOT), karena budidaya jagung merupakan usaha pokok bagi petani sehingga sering dilakukan selain itu kondisi tanah juga sudah gembur maka hanya perlu dilakukan pemberantasan gulma.

\section{B. Rumusan Masalah}

1. Berapa pendapatan petani jagung antara sistem olah tanah sempurna dengan sistem tanpa olah tanah (TOT) di Kabupaten OKU Timur.

2. Bagaimana komparasi pengelolaan tanaman jagung antara sistem olah tanah sempurna dengan sistem tanpa olah tanah (TOT) di Kabupaten OKU Timur.

3. Bagaimanakah tingkat kelayakan usaha budidaya jagung antara sistem olah tanah sempurna dengan sistem tanpa olah tanah (TOT) di Kabupaten OKU Timur.

\section{Tujuan dan Kegunaan}

1. Untuk mengetahui pendapatan petani petani jagung antara sistem olah tanah sempurna dengan sistem tanpa olah tanah (TOT) di Kabupaten OKU Timur.

2. Untuk mengetahui komparasi pengelolaan tanaman jagung antara sistem olah tanah sempurna dengan sistem tanpa olah tanah (TOT) di Kabupaten OKU Timur.

3. Untuk mengetahui tingkat kelayakan usaha budidaya jagung antara sistem olah tanah sempurna dengan sistem tanpa olah tanah (TOT) di Kabupaten OKU Timur.

\section{Model Pendekatan}

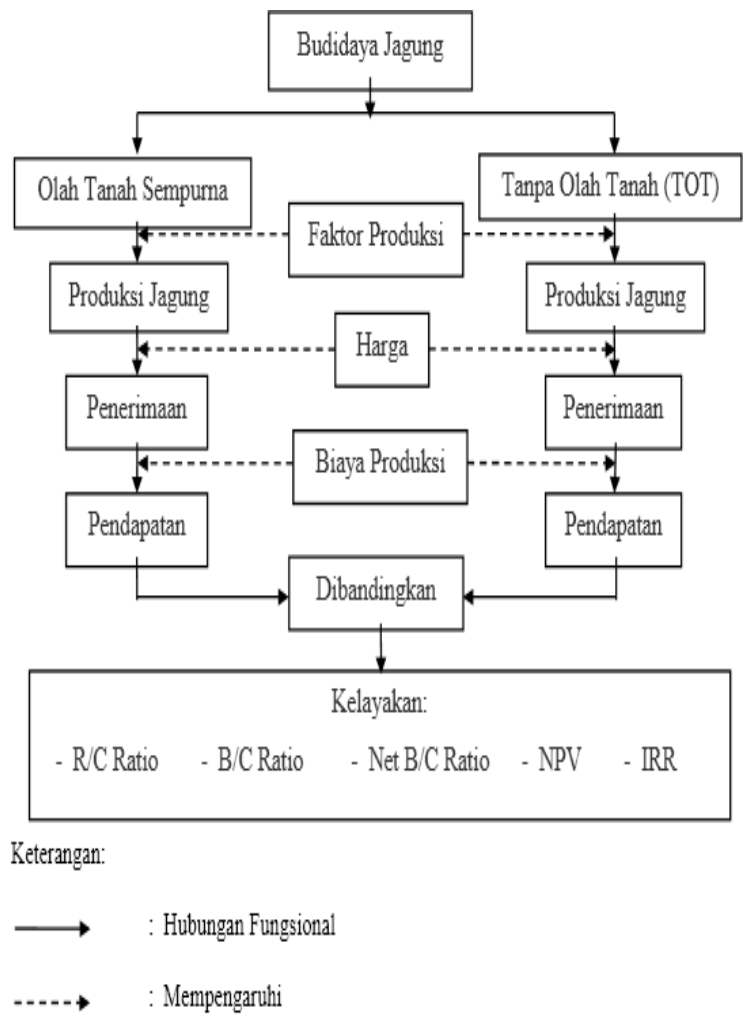

Gambar 1. Model pendekatan penelitian secara diagramatik

\section{METODOLOGI PENELITIAN}

\section{A. Tempat dan Waktu}

Penelitian ini akan dilaksanakan di Bulan April 2015 sampai dengan Bulan Juni 2015 pada usahatani budidaya jagung baik dengan sistem olah tanah sempurna maupun dengan sistem tanpa olah tanah (TOT) yang ada di Kabupaten OKU Timur. 


\section{B. Metode Penelitian}

Metode yang akan digunakan dalam penelitian ini adalah metode survei yang terpusat pada usahatani budidaya jagung baik dengan sistem tanpa olah tanah (TOT) maupun dengan sistem olah tanah sempurna di Kabupaten OKU Timur. Menurut Etta dan Sopiah (2010), metode survey merupakan metode penelitian mengenai status subjek penelitian, yang berkenaan dengan fase spesifik atau khas dari keseluruhan petani subjek penelitian baik berupa individu, kelompok maupun masyarakat.

\section{Metode Penarikan Contoh}

Metode penarikan contoh yang digunakan adalah metode survei dengan mengguanakan sample daerah pada lokasi penelitian di Kabupaten OKU Timur dan yang menjadi peserta adalah petani jagung dengan sistem tanpa olah tanah (TOT) dan sistem olah tanah sempurna yang ada di Kabupaten OKU Timur. Hal tersebut berdasarkan jumlah sample yang diambil adalah 40 sample petani budidaya jagung dengan sistem tanpa olah tanah (TOT) dari 485 populasi, dan 24 sample petani budidaya jagung dengan sistem olah tanah sempurna dari 48 populasi. Rumus yang digunakan untuk mencari $\mathrm{n}$ (sample) dari $\mathrm{N}$ (populasi), menurut Etta dan Sopiah (2010) adalah:

$n_{1}=\frac{\mathrm{N}_{1}}{1+\mathrm{N}_{1}(\mathrm{e})^{2}} \quad$ dan $\quad n_{2}=\frac{\mathrm{N}_{2}}{1+\mathrm{N}_{2}(\mathrm{e})^{2}}$

Dimana:

$\mathrm{n}=$ Sample

$\mathrm{N}=$ Populasi

$\mathrm{e}=$ Tingkat eror $(0,15)$

\section{Metode Pengolahan Data}

Data yang diperoleh dari penelitian akan dikelompokan kemudian diolah secara tabulasi, yaitu menghitung besarnya biaya produksi, penerimaan, dan pendapatan baik petani budidaya jagung baik dengan sistem tanpa olah tanah (TOT) maupun dengan sistem olah tanah sempurna, rumus yang akan diguanakan adalah sebagai berikut:

1. Untuk mengetahui biaya produksi, penerimaan, dan pendapatan :

a. Menurut Ibrahim (2009), untuk mengetahui biaya produksi maka digunakan rumus:

$\mathrm{TC}=\mathrm{FC}+\mathrm{VC}$

Dimana:

$\mathrm{TC}=$ Total Cost (Total Biaya)

$\mathrm{FC}=$ Fixed Cost (Biaya Tetap)

$\mathrm{VC}=$ Variable Cost (Biaya Tidak Tetap) b. Menurut Soekartawi (2001), untuk mengetahui besarnya penerimaan maka digunakan rumus :

$\mathrm{R}=\mathrm{Y} \times \mathrm{P}$

Dimana:

$\mathrm{R}=$ Revenue (Penerimaan)

$\mathrm{Y}=$ Yield (Hasil Produksi)

$\mathrm{P}=$ Price (Harga)

c.Menurut Ibrahim (2009), untuk mengetahui besarnya pendapatan maka digunakan rumus:

$\mathrm{I}=\mathrm{R}-\mathrm{TC}$.

Dimana:

$\mathrm{I}=$ Income (Pendapatan)

$\mathrm{R}=$ Revenue (Penerimaan)

$\mathrm{TC}=$ Total Cost (Total Biaya)

2. Sedangkan untuk mengetahui komparasi pengelolaan tanaman jagung sistem olah tanah sempurna dengan sistem tanpa olah tanah (TOT), dilakukan dengan cara membandingkan hasil pendapatan dari kedua sistem pengelolaan tanaman jagung tersebut, apakah terdapat perbedaan yang signifikan atau tidak.

3. Untuk mengetahui kelayakan usaha:

a. Menurut Zulkarnain (2005), untuk mengetahui kelayakan penerimaan maka digunakan rumus:

$$
\mathrm{R} / \mathrm{C} \text { Ratio }=\frac{\text { Revenue }(\text { Penerimaan })}{\text { Cost }(\text { Biaya })}
$$

Dimana:

Revenue: Penerimaan (Rp)

Cost : Biaya (Rp)

Dengan kriteria :

$\mathrm{R} / \mathrm{C}>1$ : Usahatani menguntungkan

$\mathrm{R} / \mathrm{C}<1$ : Usahatani tidak menguntungkan

$\mathrm{R} / \mathrm{C}=1$ : Usahatani Impas

Usahatani budidaya jagung baik dengan sistem tanpa olah tanah (TOT) maupun sistem olah tanah sempurna di Kabupaten OKU timur dikatakan menguntungkan apabila R/C lebih besar dari satu, sebaliknya apabila nilai R/C kurang dari satu maka usahatani tidak menguntungkan (rugi) dan dikatakan impas apabila nilai $\mathrm{R} / \mathrm{C}$ sama dengan satu.

b. Menurut Zulkarnain (2005), untuk mengetahui kelayakan pendapatan maka digunakan rumus:

$$
\mathrm{B} / \mathrm{C} \text { Ratio }=\frac{\text { Benefit(Pendapatan) }}{\text { Cost }(\text { Biaya })}
$$

Dimana:

Benefit : Pendapatan (Rp)

Cost : Biaya (Rp)

Dengan Kriteria:

B/C Ratio $>0$ : Usahatani menguntungkan

$\mathrm{B} / \mathrm{C}$ Ratio $<0$ : Usahatani rugi

$\mathrm{B} / \mathrm{C}$ Ratio $=0$ : Usahatani impas 
Usahatani budidaya jagung baik dengan sistem tanpa olah tanah (TOT) maupun dengan sistem olah tanah sempurna di Kabupaten OKU timur dikatakan layak apabila B/C lebih besar dari nol, sebaliknya apabila nilai B/C kurang dari nol maka usahatani tidak layak dan dikatakan impas apabila nilai $\mathrm{B} / \mathrm{C}$ sama dengan nol.

c.Menurut Gittinger (2006), untuk mengetahui Net Present Value maka bisa menggunakan rumus:

$$
\mathrm{NVP}=\left[\sum_{t=1}^{t=n} \frac{B t-C t}{(1+i)}\right]-K o
$$

Dimana:

$\Sigma=$ Sigma (Jumlah)

$\mathrm{Bt}=$ Pendapatan pada tahun $\mathrm{t}$

$\mathrm{Ct}=$ Biaya Total Usahatani pada tahun $\mathrm{t}$

$\mathrm{t}=\mathrm{n}=$ Umur Ekonomis Investasi

$\mathrm{t}=1=$ Umur pertama investasi

$(1+\mathrm{i})^{\mathrm{t}}=$ Discounting faktor (faktor bunga)

Ko = Initial investment (modal pendahuluan)

Dengan Kriteria:

Diterima apabila NPV $>0$

Ditolak apabila NPV $<0$

Kemungkinan diterima apabila NPV $=0$

d. Menurut Kadariah (2001), untuk mengetahui tingkat pengembalian modal usaha maka digunakan rumus Internal Rate of Return yaitu:

$$
\mathrm{IRR}=i_{1}\left\{\frac{\left(N P V_{1}\right)}{\left(N P V_{1}\right)-\left(N P V_{2}\right)} x i_{1}-i_{2}\right\}
$$

Dimana:

IRR $=$ Tingkat pengembalian usaha

$\mathrm{i}_{1}=$ Discont faktor yang digunakan untuk menghasilkan present value positif

$\mathrm{i}_{2}=$ Discont faktor yang digunakan untuk menghasilkan present value negative

$\mathrm{NPV}_{1}=$ Present value positive

$\mathrm{NPV}_{2}=$ Present value negative

Dengan Kriteria:

Apabila IRR > Cost of Capital, maka investasi dianggap layak

Apabila IRR < Cost of Capital, maka investasi dianggap tidak layak

Apabila IRR = Cost of Capital, maka investasi balik modal.

e.Menurut Zulkarnain (2005), untuk menganalisis efisiensi atau kelayakan menggunakan rumus Net Benefit Cost Ratio (Net B/C) yaitu:

$$
\text { Net B/C Ratio }=\frac{\sum_{t=1}^{t=n}\left(\frac{B t-C t}{(1+1) t}\right)}{\sum_{t=1}^{t=1}\left(\frac{B t-C t}{(1+1) t}\right)}
$$

Dimana:

$\Sigma \quad=$ Sigma (Jumlah)

$\mathrm{Bt}=$ Pendapatan pada tahun $\mathrm{t}$

$\mathrm{Ct}=$ Biaya Total Usahatani pada tahun $\mathrm{t}$

$\mathrm{t}=\mathrm{n}=$ Umur Ekonomis Investasi

$\mathrm{t}=1=$ Umur pertama investasi

$(1+\mathrm{i})^{\mathrm{t}}=$ Discounting factor (faktor bunga)

Dengan Kriteria:

Net B/C Ratio > 0 : Usaha tersebut boleh dilaksanakan karena menguntungkan (Feasible)

Net B/C Ratio < 0 : Usaha tersebut ditolak karena menguntungkan (Non Feasible)

Net B/C Ratio $=0$ : Usaha tersebut balik modal persis sama dengan biaya yang dikeluarkan (Break Event Point).

\section{HASIL DAN PEMBAHASAN}

\section{A. Analisis Usaha Pengelolaan Jagung dengan Sistem Tanpa Olah Tanah (TOT) dan Sistem Olah Tanah Sempurna di Kabupaten OKU Timur.}

\section{Analisis Total Biaya Produksi (Total Cost)}

Menurut Mulyadi (2007), biaya produksi adalah semua pengeluaran yang dilakukan oleh perusahaan untuk faktor-faktor produksi, sehingga memperoleh output. Sedangkan, menurut Kusnadi (2006), biaya produksi adalah semua pengorbanan yang perlu dilakukan oleh produsen/perusahaan untuk suatu proses produksi, yang dinyatakan dengan satuan uang menurut harga pasar yang berlaku, baik yang sudah terjadi maupun yang akan terjadi. Korbanan atau biaya ini berada posisi yang harus seefesien mungkin agar mempunyai keuntungan yang optimal.

Biaya tetap adalah biaya yang tidak habis dalam satu kali proses produksi, yaitu biaya sewa lahan dan total biaya penyusutan alat. Sedangkan biaya variabel adalah biaya yang habis dalam satu kali proses produksi, diantaranya biaya sarana produksi dan tenaga kerja, dan biaya sarana produksi dapat berupa benih jagung, pupuk, dan pengendali Organisme Pengganggu Tanaman (OPT).

\begin{tabular}{|c|c|c|c|}
\hline No. & Uraian & $\begin{array}{c}\text { Sistem } \\
\text { Tanpa Olah Tanah } \\
\text { (TOT) (Rp) }\end{array}$ & $\begin{array}{c}\text { Sistem } \\
\text { Olah Tanah } \\
\text { Sempurna }(\mathrm{Rp})\end{array}$ \\
\hline 1. & $\begin{array}{l}\text { Biaya Tetap } \\
\text { Sewa Tempat Usaha } \\
\text { Biava Penvusutan Alat (BPA) }\end{array}$ & $\begin{array}{r}1.088 .896,- \\
1.024 .306,- \\
61.591-\end{array}$ & $\begin{array}{r}1.086 .254,- \\
1.024 .306,- \\
987.065-\end{array}$ \\
\hline 2. & $\begin{array}{l}\text { Biaya Variabel } \\
\text { Biaya Sarana Produksi } \\
\text { Biaya Tenaga Kerja }\end{array}$ & $\begin{array}{r}10.208 .029,- \\
5.481 .983,- \\
4.726 .046,-\end{array}$ & $\begin{array}{l}11.912 .434,- \\
5.473 .080,- \\
6.439 .354,-\end{array}$ \\
\hline 3. & Total Biaya $(1+2)$ & 11.296.925,- & 12.998.688,- \\
\hline
\end{tabular}

Tabel 1. Rincian Rata-rata Biaya Produksi Usahatani Jagung Pertahun.

Sumber: Data Primer (Diolah), 2015. 
Berdasarkan tabel di atas diketahui ratarata besarnya biaya tetap yang dikeluarkan petani jagung dengan sistem Tanpa Olah Tanah (TOT) adalah Rp. 1.088.896,-/Thn yang digunakan untuk sewa tempat usaha Rp. 1.024.306,- dan biaya penyusutan alat Rp. 61.591,-/Thn. Selain biaya tetap dikeluarakan juga biaya variabel sebesar Rp. 10.208.029,-/Thn diantaranya untuk biaya sarana produksi sebesar Rp. 5.481.983,-/Thn serta untuk biaya tenaga kerja mulai sebesar Rp. 4.726.046,/Thn,-. Sehingga total dari keseluruhan biaya yang dikeluarkan selama satu kali poses produksi adalah jumlah dari biaya tetap ditambah dengan jumlah biaya variabel maka total biaya produksi adalah Rp. 11.296.925,-/Thn.

Sedangkan rata-rata besarnya biaya tetap yang dikeluarkan oleh petani jagung dengan sistem Olah Tanah Sempurna adalah Rp. 1.086.254,-/Thn yang digunakan untuk sewa tempat usaha Rp. 1.024.306,- dan biaya penyusutan alat Rp. 987.065,-/Thn. Selain biaya tetap dikeluarakan juga biaya variabel sebesar Rp. 11.912.434,-/Thn diantaranya untuk biaya sarana produksi sebesar Rp. 5.473.080,-/Thn serta untuk biaya tenaga kerja mulai sebesar Rp. 6.439.354,/Thn,-. Sehingga total dari keseluruhan biaya yang dikeluarkan selama satu kali poses produksi adalah jumlah dari biaya tetap ditambah dengan jumlah biaya variabel maka total biaya produksi adalah Rp. 12.998.688,-/Thn.

\section{Produksi, Harga, Penerimaan, dan Pendapatan Pertahun}

Hasil penelitian di lapangan untuk produksi, penerimaan dan pendapatan usaha pengelolaan tanaman jagung dengan sistem olah tanah sempurna dan sistem tanpa olah tanah (TOT) dapat dilihat pada tabel berikut ini:

Tabel 2. Rincian Rata-rata Produksi, Harga, Penerimaan, dan Pendapatan Usahatani Jagung Pertahun.

\begin{tabular}{llll}
\hline No. & \multicolumn{1}{c}{ Uraian } & \multicolumn{1}{c}{$\begin{array}{c}\text { Sistem } \\
\text { Tanpa Olah Tanah } \\
\text { (TOT) }\end{array}$} & $\begin{array}{c}\text { Sistem } \\
\text { Olah Tanah Sempurna }\end{array}$ \\
\hline 1. & Produksi & $12.500 \mathrm{~kg}$ & $12.500 \mathrm{~kg}$ \\
2. & Harga & Rp. $2.327,-/ \mathrm{kg}$ & Rp. $2.321,-\mathrm{kg}$ \\
3. & Total Biaya Produksi (Rp/PP) & Rp. $11.296 .925,-$ & Rp. 12.998.688,- \\
4. & Penerimaan (Rp/PP) & Rp. $29.139 .583,-$ & Rp. $31.819 .792,-$ \\
5. & Pendapatan (Rp/PP) & Rp. $17.842 .658,-$ & Rp. 18.821.104,- \\
\hline
\end{tabular}

Sumber: Data Primer (Diolah), 2015.

Setiap tahun produksi jagung dengan sistem Tanpa Olah Tanah (TOT) rata-rata mencapai $12.500 \mathrm{~kg}$ dengan harga rata-rata $\mathrm{Rp}$. $2.327,-/ \mathrm{kg}$, sedangkan produksi jagung dengan sistem olah tanah sempurna rata-rata sebanyak
$12.500 \mathrm{~kg}$ dengan harga rata-rata Rp. $2.321,-/ \mathrm{kg}$. Harga akan mempengaruhi besarnya penerimaan yang diterima oleh petani jagung. Produksi jagung baik dengan sistem Tanpa Olah Tanah (TOT) maupun dengan sistem Olah Tanah Sempurna selama ini dibeli langsung oleh pedagang pengepul yang datang langsung ke lokasi. Hal tersebut dilakukan karena untuk menekan biaya produksi agar bisa sekecil mungkin.

Penerimaan adalah jumlah penghasilan produksi dalam satuan fisik dikalikan dengan harga jual, yang didefinisikan sebagai nilai uang yang diterima. Tujuan akhir dari pengelolaan usahatani adalah perolehan besarnya pendapatan tunai atau proporsi penerimaan yang dapat digunakan sebagai perbandingan keberhasilan antar pelaku usaha (Saragih, 2001). Penerimaan yang diterima oleh petani jagung dengan sistem Tanpa Olah Tanah (TOT) rata-rata sebesar Rp. 29.139.583,-/Thn, sedangkan biaya produksi yang dikeluarkan adalah Rp. 11.296.925,-./Thn. Besarnya biaya produksi yang dikeluarkan akan mempengaruhi pendapatan yang diterima oleh petani. Besarnya pendapatan yang diperoleh adalah Rp. 17.842.658,-/Thn (Rp. 5.947.553,- atau Rp. 1.486.888,-). Sedangkan penerimaan yang diterima oleh petani jagung dengan sistem olah tanah sempurna rata-rata sebesar Rp. 31.819.792,/Thn, sedangkan biaya produksi yang dikeluarkan adalah Rp. 12.998.688,-./Thn. Besarnya biaya produksi yang dikeluarkan akan mempengaruhi pendapatan yang diterima oleh petani. Besarnya pendapatan yang diperoleh adalah $\mathrm{Rp}$. 18.821.104,-/Thn (Rp. 6.273.701,- atau Rp. 1.568.425,-). Pendapatan yang lebih besar merupakan alasan bagi pelaku usaha untuk menambah cadangan sebuah usaha baru.

\section{Analisis Komparasi Pendapatan Pertahun}

Analisis komparasi usaha pengelolaan tanaman jagung dengan sistem Tanpa Olah Tanah (TOT) dengan sistem olah tanah sempurna dari tahun 2011 sampai dengan tahun 2016 dilakukan untuk mengetahui perbedaan besarnya pendapatan yang diperoleh dari usahatani jagung setiap musim tanam, lebih jelasnya dapat dilihat pada tabel berikut.

Tabel 3. Rata-rata Komparasi Pendapatan Usahatani Jagung Pertahun.

\begin{tabular}{rrrrr}
\hline No. & Tahun & $\begin{array}{c}\text { Pendapatan } \\
\text { TOT }\end{array}$ & $\begin{array}{c}\text { Pendapatan } \\
\text { OTS }\end{array}$ & \multicolumn{1}{c}{$\begin{array}{c}\text { Selisih } \\
\text { OTS dengan TOT }\end{array}$} \\
\hline 1 & 2011 & $14,976,800$ & $16,545,736$ & $1,568,936$ \\
2 & 2012 & $17,623,921$ & $18,626,912$ & $1,002,991$ \\
3 & 2013 & $18,209,930$ & $19,596,027$ & $1,386,097$ \\
4 & 2014 & $18,541,019$ & $19,431,582$ & 890,563 \\
5 & 2015 & $18,143,711$ & $18,950,652$ & 806,941 \\
6 & 2016 & $19,560,569$ & $19,775,714$ & 215,145 \\
\hline$\Sigma$ & & $107,055,950$ & $112,926,623$ & $5,870,673$ \\
$\bar{Y}$ & & $17,842,658$ & $18,821,104$ & 978,446 \\
\hline
\end{tabular}

Sumber: Data Primer (Diolah), 2015. 
Analisis komparasi usaha pengelolaan jagung dengan sistem Tanpa Olah Tanah (TOT) dilakukan dengan tujuan untuk perbedaan pendapatan, sehingga akan diketahui pendapatan usahatani jagung dengan sistem manakah yang lebih besar. Berdasarkan tabel di atas diketahui bahwa pendapatan dari usaha pengelolaan tanaman jagung dengan sistem olah tanah sempurna (OTS) lebih besar dibandingkan dengan sistem tanpa olah tanah (TOT). Besarnya selisih pendapatan rata-rata setiap musim tanam diperoleh sebesar Rp. 978.446,-/MT.

\section{Analisis Keuntungan dan Kelayakan Usaha} Pengelolaan Jagung

Usaha pengelolaan jagung dengan sistem Tanpa Olah Tanah (TOT) dan sistem olah tanah sempurna setelah dilakukan analisis perhitungan dan kunjungan di lapangan maka dapat dikatakan menguntungkan dan layak untuk dilakukan, karena berdasarkan segi ekonomi memiliki keuntungan, seperti pada tabel berikut:

Tabel 4. Rata-rata Tingkat Keuntungan dan Kelayakan Usahatani Jagung.

\begin{tabular}{|c|c|c|c|}
\hline No. & Uraian & $\begin{array}{c}\text { Sistem } \\
\text { Tanpa Olah Tanah (TOT) }\end{array}$ & $\begin{array}{c}\text { Sistem } \\
\text { Olah Tanah Sempurna }\end{array}$ \\
\hline 1. & R/C Ratio & 2,58 & 2,45 \\
\hline 2. & B/C Ratio & 1,58 & 1,45 \\
\hline
\end{tabular}

Sumber: Data Primer (Diolah), 2015.

Berdasarkan tabel di atas usaha pengelolaan jagung dengan sistem Tanpa Olah Tanah (TOT) memiliki tingkat keuntungan penerimaan yang nilainya lebih dari 1 yaitu ratarata sebesar 2,58 yang artinya usahatani jagung dengan sistem TOT menguntungkan karena setiap Rp. 100,- modal yang digunakan akan diperoleh penerimaan sebesar Rp. 285,-. Berdasarkan tingkat keuntungan dari pendapatan nilainya lebih dari 0 yaitu rata-rata sebesar 1,85 yang artinya usaha tersebut layak untuk dikembangkan karena setiap Rp. 100,- modal yang digunakan diperoleh pendapatan sebesar Rp. 185,-.

Sedangkan pada usaha pengelolaan jagung dengan sistem Olah Tanah Sempurna memiliki tingkat keuntungan penerimaan yang lebih kecil meskipun nilainya juga lebih dari 1 yaitu rata-rata sebesar 2,45 yang artinya usahatani jagung dengan sistem olah tanah sempurna juga menguntungkan karena setiap Rp. 100,- modal yang digunakan akan diperoleh penerimaan sebesar Rp. 245,-. Sedangkan berdasarkan tingkat keuntungan dari pendapatan nilainya lebih dari 0 yaitu rata-rata sebesar 1,45 yang artinya usaha tersebut layak untuk dikembangkan karena setiap Rp. 100,- modal yang digunakan diperoleh pendapatan sebesar Rp. 145,-. Sehingga apabila dibandingkan maka usaha pengelolaan jagung dengan sistem Tanpa Olah Tanah (TOT) lebih layak untuk dilakukan karena selain memiliki keuntungan yang lebih besar biaya produksi yang dikeluarkan juga lebih kecil dibandingkan usaha pengelolaan jagung dengan sistem olah tanah sempurna.

Selanjutnya untuk mengetahui nilai kelayakan usaha pengelolaan jagung dengan sistem Tanpa Olah Tanah (TOT) dan sistem olah tanah sempurna pada tahun-tahun yang akan mendatang, dihitung dengan menggunakan rumus NPV, IRR dan Net B/C sehingga diketahui perkiraan pendapatan yang akan diterima pada tahun-tahun yang akan mendatang dengan asumsi puncak produksi jagung dengan sistem Tanpa Olah Tanah (TOT) semakin menurun mulai tahun ketiga dan keempat dan untuk sistem olah tanah sempurna produksi jagung akan menurun pada tahun ketiga dan keempat. Analisis NPV, IRR dan Net B/C sama-sama dihitung sejak awal usaha yaitu tahun 2011.

Tabel 5. Nilai NPV usaha pengelolaan jagung dengan sistem Tanpa Olah Tanah (TOT).

\begin{tabular}{|c|c|c|c|c|c|c|c|c|c|c|}
\hline Tahun & Investasi & $\begin{array}{c}\text { Net } \\
\text { Benefit }\end{array}$ & $\begin{array}{c}\mathrm{Cf} 18 \\
\%\end{array}$ & FV $18 \%$ & $\begin{array}{c}\text { Df } \\
18 \%\end{array}$ & PV $18 \%$ & $\begin{array}{c}\mathrm{Cf} \\
74 \%\end{array}$ & FV $74 \%$ & $\begin{array}{c}\text { Df } \\
74 \%\end{array}$ & PV $74 \%$ \\
\hline 12016 & & $19,560,569$ & & & 0.847 & $16,576,753$ & & & 0.575 & $11,241,706$ \\
\hline 02015 & 907,650 & $18,143,711$ & & $17,236,061$ & & & & $17,236,061$ & & \\
\hline 12014 & & $18,541,019$ & 1.180 & $21,878,402$ & & & 1.740 & $32,261,373$ & & \\
\hline 22013 & & $18,209,930$ & 1.392 & $25,355,507$ & & & 3.028 & $55,132,384$ & & \\
\hline 32012 & & $17,023,921$ & 1.643 & $28,956,666$ & & & 5.268 & $92,843,239$ & & \\
\hline $4 \quad 2011$ & $38,014,475$ & $14,976,800$ & 1.939 & $44,664,932$ & & & 9.166 & $(211,171,663)$ & & \\
\hline & & & $\begin{array}{l}\text { Total } \\
\text { NPV } \\
\text { (2FV+ } \\
\text { (PV) }\end{array}$ & $48,761,704$ & & $65,338,458$ & & $(13,698,606)$ & & $(2,456,900)$ \\
\hline
\end{tabular}

Sumber: Data Primer (Diolah), 2015.

Tabel 6. Nilai IRR usaha pengelolaan jagung dengan sistem Tanpa Olah Tanah (TOT).

\begin{tabular}{rrr}
\hline No & Uraian & \multicolumn{1}{c}{ Nilai } \\
\hline 1 & NPV 18\% & $65,338,458$ \\
2 & NPV 74\% & $(2,456,900)$ \\
\hline & IRR & $44,99 \%$ \\
\hline
\end{tabular}

Sumber: Data Primer (Diolah), 2015.

Tabel 7. Nilai Net B/C usaha pengelolaan jagung dengan sistem Tanpa Olah Tanah (TOT).

\begin{tabular}{ll}
\hline Uraian & Nilai \\
\hline Net B/C & \\
\hline
\end{tabular}

Sumber: Data Primer (Diolah), 2015. 
Tabel 8. Nilai NPV usaha pengelolaan jagung dengan sistem Olah Tanah Sempurna.

\begin{tabular}{|c|c|c|c|c|c|c|c|c|c|}
\hline Talune Inrestasi & $\begin{array}{c}\text { Net } \\
\text { Bentefit }\end{array}$ & $\begin{array}{l}C 1.18 \\
\%\end{array}$ & FV 18\% & $\begin{array}{l}\text { Df } \\
18 \% \\
\end{array}$ & PV $18 \%$ & $\begin{array}{l}C 884 \\
\%\end{array}$ & EN84\% & $\begin{array}{l}D f \\
84 \%\end{array}$ & PV84\% \\
\hline 12016 & $19,75,714$ & & & & $16,790,080$ & & & & 10,74,071 \\
\hline $0 \quad 2015 \quad 941,291$ & $18,50,652$ & & $18,009,361$ & & & & $18,009,361$ & & \\
\hline 12014 & $19,431,582$ & 1.180 & 1) 22,290,267 & & & 1.840 & $35,734,111$ & & \\
\hline 22013 & $10,966,027$ & 1.392 & $27,285,008$ & & & 3386 & $66,344,309$ & & \\
\hline 32012 & $18,66,912$ & 1.643 & $30,004,612$ & & & 6.30 & $116,036,423$ & & \\
\hline $4 \quad 201138,125,000$ & $16,45,736$ & 1.939 & 41,837,397 & & & 11.462 & $(247,34,725)$ & & \\
\hline & & $\begin{array}{l}\text { Total } \\
\text { IPV } \\
(\mathrm{CNV}+ \\
{[\mathrm{PN})}\end{array}$ & 360991,351 & & $73,750,43$. & & $(11,203,2521)$ & & $(455,8511)$ \\
\hline
\end{tabular}

Sumber: Data Primer (Diolah), 2015.

Nilai NPV pada suku bunga bank $18 \%$ diperoleh nilai Rp. 65.338.458,- yang artinya pada suku bunga bank $18 \%$ investasi pada usaha pengelolaan jagung dengan sistem Tanpa Olah Tanah (TOT) lebih menguntungkan dibandingkan dengan menginvestasikan uang di bank. Nilai IRR diperoleh sebesar 44,99\% yang artinya suku bunga yang diterima lebih besar dari suku bunga bank yang berlaku yaitu $18 \%$ sehingga usaha pengelolaan jagung dengan sistem Tanpa Olah Tanah (TOT) semakin layak untuk dikembangkan. Sedangkan untuk mengetahui nilai perbandingan $\mathrm{PV}$ positif dan PV negatif diperoleh Net B/C sebesar 0,81 yang berarti usaha feasible (usaha boleh dilaksanakan karena menguntungkan).

Tabel 9. Nilai IRR usaha pengelolaan jagung dengan sistem Olah Tanah Sempurna.

\begin{tabular}{lll}
\hline No & Uraian & Nilai \\
\hline \multirow{3}{*}{1} & NPV & \\
& $18 \%$ & $73,750,431$ \\
2 & NPV & \\
\hline IRR & $84 \%$ & $(455,851)$ \\
\hline
\end{tabular}

Sumber: Data Primer (Diolah), 2015.

Tabel 10. Nilai Net B/C usaha pengelolaan jagung dengan sistem Olah Tanah Sempurna.

\begin{tabular}{ll}
\hline Uraian & Nilai \\
\hline Net B/C & \\
\hline
\end{tabular}

Sumber: Data Primer (Diolah), 2015.

Usaha pengelolaan jagung dengan sistem olah tanah sempurna memiliki nilai NPV pada suku bunga bank sebesar 18\% sehingga diperoleh nilai Rp. 73.750.431,-. Nilai IRR diperoleh sebesar $45,83 \%$ yang artinya suku bunga yang diterima lebih besar dari suku bunga bank yang berlaku yaitu $18 \%$ sehingga usaha pengelolaan jagung dengan sistem olah tanah sempurna semakin layak untuk dikembangkan. Sedangkan untuk mengetahui nilai perbandingan $\mathrm{PV}$ positif dan PV negatif diperoleh Net B/C sebesar 1 yang berarti usaha pengelolaan jagung dengan sistem olah tanah sempurna feasible (usaha boleh dilaksanakan karena menguntungkan).

Berdasarkan hal tersebut di atas maka usaha pengelolaan jagung baik dengan sistem Tanpa Olah Tanah (TOT) maupun dengan sistem olah tanah sempurna memiliki keuntungan sehingga layak untuk dilakukan, akan tetapi usaha pengelolaan jagung dengan sistem Tanpa Olah Tanah (TOT) lebih layak untuk dilakukan.

\section{IV.KESIMPULAN DAN SARAN}

\section{A. Kesimpulan}

Berdasarnya hasil penelitian dan analisis yang telah dilakukan, maka dapat ditarik kesimpulan sebagai berikut:

1. Rata-rata dikeluarkan biaya produksi untuk kegiatan usaha pengelolaan jagung dengan sistem Tanpa Olah Tanah (TOT) sebesar Rp. 11.296.925,-/Thn, dengan biaya tetap sebesar Rp. 1.088.896,-/Thn, dan biaya variabel sebesar Rp. 10.208.029,-/Thn. Penerimaan diperoleh Rp. 29.139.583,-/Thn maka diperoleh pendapatan sebesar Rp. 17.842.658,/Thn (Rp. 5.947.553,-/MT atau Rp. 1.486.888,/Bln). Sedangkan rata-rata biaya produksi pada kegiatan usaha pengelolaan jagung dengan sistem olah tanah sempurna sebesar Rp. 12.998.688,-/Thn, dengan biaya tetap sebesar Rp. 1.086.254,-/Thn, dan biaya variabel sebesar Rp. 11.912.434,-/Thn. Sedangkan penerimaan diperoleh Rp. 31.819.792,-/Thn maka diperoleh pendapatan sebesar Rp. 18.821.104,-/Thn (Rp. 6.273.701,-/MT atau Rp. 1.568.425,-/Bln).

2. Nilai komparasi usaha pengelolaan jagung dengan sistem tanpa olah tanah (TOT) adalah Rp. 17.842.658,-/MT. Sedangkan pada usaha pengelolaan jagung dengan sistem olah tanah sempurna adalah Rp. 18.821.104,-/MT yang diperoleh dari dari selisih nilai akhir dengan biaya produksi. Sehingga, terdapat perbedaan 
pendapatan sebesar Rp. 978.446,-/MT (Rp. 244.611,-/Bulan).

3. Usaha pengelolaan jagung dengan sistem Tanpa Olah Tanah (TOT) dan olah tanah sempurna yang ada di Kabupaten OKU Timur dapat dikatakan menguntungkan dan layak, karena rata-rata diperoleh nilai R/C Ratio 2,58 yang berarti > 1 maka usaha dinyatakan menguntungkan, dan juga diperoleh nilai $\mathrm{B} / \mathrm{C}$ Ratio 1,58 yang berarti > 0 , maka usaha dinyatakan layak. Selain itu, diperoleh NPV pada suku bunga bank $18 \%$ (Rp. 65.338.458,-) dengan nilai IRR 44,99 \% dan nilai Net B/C sebesar 0,81 yang berati feasible atau usaha dapat dilakukan karena menguntungkan. Sedangkan usaha pengelolaan jagung dengan sistem olah tanah sempurna rata-rata diperoleh nilai R/C Ratio 2,45 yang berarti > 1 maka usaha dinyatakan menguntungkan, dan juga diperoleh nilai B/C Ratio 1,45 yang berarti > 0 , maka usaha dinyatakan layak. Selain itu, diperoleh NPV pada suku bunga bank $18 \%$ (Rp. 73.750.431,-) dengan nilai IRR 45,83\% dan nilai Net B/C sebesar 1 yang berati feasible atau usaha dapat dilakukan karena menguntungkan.

\section{B.Saran}

Saran yang dapat diberikan dari hasil penelitian yang telah dilakukan adalah:

1. Para petani jagung sebaiknya menggunakan sistem Tanpa Olah Tanah (TOT) karena lebih menguntungkan dan layak untuk dikembangkan.

2. Para petani jagung sebaiknya bekerja sama dengan pemerintah terutama untuk menjaga tanaman jagung agar tidak terserang hama.

\section{DAFTAR PUSTAKA}

Arsyad, L. 2003. Ekonomi Manajerial, Edisi Kelima. Balai Pustaka. Yogyakarta.

Dariah, Ai. 2009. Konservasi Tanah pada Lahan Tegalan. Balai Penelitian Tanah. Bogor.

Departemen Pertanian dan Ketahanan Pangan. 2001. Modul Kajian dalam Mempertahankan Produksi Pangan Nasional. Jakarta.

Departemen Pertanian. 2007. Modul Pelatihan Kebijakan Pembangunan Pertanian. Jakarta.
Etta, M. S. dan Sopiah. 2010. Metodelogi Penelitian. ANDI. Yogyakarta.

Faizul. 2009. Ekonomi Makro. Graha Ilmu. Yogyakarta.

Gittinger, JP. 2006. Analisa Proyek-Proyek Pertanian (terjemahan). The John Hopkins University.

Hadiyanto, I. 2003. Bertanam Jagung. Balai Pustaka (Persero). Jakarta.

Hernanto, F. 1997. Ilmu Usahatani. Penebar Swadaya. Jakarta.

Ibrahim, Y. 2009. Study Kelayakan Bisnis. Rineka. Jakarta.

Joersan. 2003. Teori Ekonomi Mikro. Salemba Empat. Jakarta.

Juanda. 2004. Paradigma Baru Pembangunan Pertanian. Raja Grafindo Persada. Jakarta.

Kadariah, R. 2001. Evaluasi Proyek Analisis Ekonomi. LPFE -UI. Jakarta.

Kartasapoetra. 2003. Dasar-dasar Ilmu Usaha. LP3ES. Jakarta.

Kusnadi. 2006. Studi Kelayakan Bisnis. Universitas Bramawijaya. Malang.

Kuswadi. 2007. Analisis Keekonomian Proyek. Andi Offset. Yogyakarta.

Manullang. 2003. Analisis Harga. LP3ES. Jakarta.

Mulyadi. 2009. Akuntansi Biaya, Edisi Kelima. Graha Ilmu. Yogyakarta.

Pardede, James P. 2009. Diversifikasi dan Sentuhan Tekhnologi Salah Satu Upaya untuk Sejahterakan Petani. Bogor.

Prabowo. 2010. Teknis Budidaya Tanaman Pangan. Kanisius. Yogyakarta.

Samoelson dan Naredhous. 2000. Pemasaran Produksi Pertanian dan Pengkajian Pemasaran Komoditas. IPB. Bogor. 
Saragih, B. 2001. Suara dari Bogor Membangun Sistem Agribisnis. Yayasan USESE bekerjasama dengan SUCOFINDO. Bogor.

Sjarkowi, F dan Marwan, S. 2004. Manajemen Agribisnis. CV. Baldad Grafitti Press. Palembang.

Sjarkowi, F. 2010. Manajemen Pembangunan Agribisnis. CV. Baldad Grafitti Press. Palembang.

Soekartawi. 2001. Prinsip Dasar Komunikasi Pertanian. UI Press. Jakarta.

Suratiyah. 2006. Faktor-faktor Produksi. PT Penebar Swadaya. Jakarta.
Teken dan Asnawi. 2005. Teori Ekonomi Makro. Erlangga. Jakarta.

Zulkarnain. 2005. Studi Kelayakan Usaha. Prehalindo. Jakarta. 